The University of Southern Mississippi

The Aquila Digital Community

Faculty Publications

3-28-2019

\title{
Self-Report QRIS: Challenges With Validation
}

Jacob A. Esplin

University of Southern Mississippi, jacob.esplin@usm.edu

Brionne G. Neilson

Southern Utah University

Ann M. Berghout Austin

Utah State University

Alexander Fronk

Utah State University

Follow this and additional works at: https://aquila.usm.edu/fac_pubs

Part of the Early Childhood Education Commons

\section{Recommended Citation}

Esplin, J. A., Neilson, B. G., Austin, A. M., Fronk, A. (2019). Self-Report QRIS: Challenges With Validation. Early Education and Development.

Available at: https://aquila.usm.edu/fac_pubs/16316

This Article is brought to you for free and open access by The Aquila Digital Community. It has been accepted for inclusion in Faculty Publications by an authorized administrator of The Aquila Digital Community. For more information, please contact Joshua.Cromwell@usm.edu. 
Self-Report QRIS: Challenges with Validation

\author{
Jacob Esplin, Ph.D. \\ Southern Mississippi University \\ Brionne Neilson, M.Ed \\ Southern Utah University \\ Ann M. Berghout Austin, Ph.D. \\ Utah State University \\ Alexander T. Fronk, MS \\ Bear River Head Start
}

We thank the Utah Agriculture Experiment Station and the Utah Office of Childcare for their support of this work. Many thanks to the Utah childcare providers for their cooperation and ongoing service to children. 
SELF-REPORT QRIS 


\begin{abstract}
Research Findings. The current study looks at the validity of a voluntary self-report Quality Rating and Improvement System (QRIS) and the characteristics of participating childcare centers. The self-reported quality indicators are compared to external ratings of quality (ECERSR) and correlated with variables such as size of center and number of state subsidy clients. ECERS-R scores were unrelated to capacity but significantly lower for centers with a large percentage of state supported clients. Regarding self-reported quality, centers frequently underreported their quality and what was claimed was not always externally validated, suggesting a self-report QRIS may not be an accurate assessment of quality. Additionally, no significant differences in quality were found between centers participating and those notparticipating in the self-report QRIS.

Practice or Policy. Self-reported childcare quality was not accurate in this study. Although providers over-reported some quality, they frequently under-reported quality, by claiming fewer indicators than external validators found. When centers are unmotivated to participate in a voluntary, self-report QRIS, when items reported are the easiest to report, and when existing quality indicators are unreported, a self-reported QRIS cannot validly reflect quality. Because providers both over reported and underreported quality criteria, it is doubtful the system truly incentivizes desired quality changes.
\end{abstract}

Keywords: center childcare; QRIS; self-report; state subsidy 
Self-Report QRIS: Challenges with Validation

Identifying the need to evaluate and improve the quality of child care (Lahti, Elicker, Zellman, \& Fiene, 2015), many states have implemented a quality rating system (QRS) or quality rating and improvement system (QRIS; to find information on a state-by-state level see, QRIS National Learning Network, 2017). This paper describes the accuracy of childcare center providers and directors when rating themselves on childcare quality indicators. Accuracy ratings are divided by center capacity and percentage of state subsidy clients, variables of interest for the funders of this study. Fidelity is evaluated by looking at external ratings of center quality compared with provider and director self-reports and correlating those with variables such as size of center, number of state subsidy clients, and center director demographics. This study is one of the first to our knowledge to examine the fidelity of a self-report QRIS system and adds an important component to the QRIS literature. The QRIS approach in the United States resulted from the failure of existing methods (e.g., licensing requirements, voluntary accreditation), including those designed for centers serving low-income families (Fuller, Loeb, Kagan, \& Carrol, 2004), to have the desired influence on quality of care (Cochran, 2007; Karoly, Zellman, \& Perlman, 2013). In the United States, as of January 2017, there are 40 statewide QRISs, including one in the District of Columbia, and three regional QRISs serving multiple states (QRIS National Learning Network, 2017).

Originally designed as a market-based strategy for improving quality of child care (Goffin \& Barnett, 2015), QRISs have been used as a method of promoting professional development and more recently as an accountability tool regarding child outcomes (Zellman \& Karoly, 2012). The structure and foci of QRISs vary greatly from one state to the next, but traditionally include the following directives: improving quality of care through defining quality 
standards; providing centers with a framework for building strong child care programs; providing financial incentives for quality improvement, training, and technical assistance; monitoring or assigning ratings based on quality standards; and delivering support and information to families, enabling parents to compare centers through transparency of quality (Lahti et al., 2015; Mitchell, 2009; Paulsell, Tout, \& Maxwell, 2013; Zellman \& Perlman, 2008). QRIS programs can be powerful as providing quality improvement supports has increased observed child care quality in as little as six months (Boller et al., 2015).

Quality ratings are sometimes summarized as an easily understood single rating of quality (Lugo-Gil et al., 2011), such as a star system. The quality standards that determine the "single score system" vary somewhat from state to state but typically include indicators that show positive associations with child outcomes (Jeon \& Buettner, 2015). Indicators in the single score system likely include adult-child ratio, structural and process ratings of the environment, group size, and quality of adult-child interactions (Tout et al., 2010). Because every state's QRIS system is unique and subject to change (Lugo-Gil et al., 2011), it is often challenging to generalize quality ratings from one state to another (Zellman \& Karoly, 2015). This would not be resolved by a national QRIS (Boller \& Maxwell, 2015) as there is no agreement on the definition of quality (Goffin \& Barnett, 2015). However, regardless of how a state implements a QRIS, the primary goal is the incremental improvement of child care with clearly defined levels of quality that parents can use to inform their choice of care (Goffin \& Barnett, 2015).

Efforts to improve quality are important, but it must improve to a sufficient level. Research has found child outcomes improve only after quality has reached certain thresholds (Burchinal, Vandergrift, Pianta, \& Mashburn, 2010; Le, Schaack, \& Setodji, 2015; Zaslow, Burchinal, Tarullo, \& Martinez-Beck, 2016). For example, Burchinal et al. (2010) found that 
once the quality of teacher-child interactions reached a traditionally recognized level of good quality, higher quality teacher-child interactions predicted increased social skills and decreased behavior issues. In lower quality classrooms where this quality threshold was not reached, higher quality teacher-child interactions did not predict better social skills and predicted slightly higher, not lower, levels of behavior issues. However, as Le et al. (2015) explain, identifying thresholds is difficult as they may vary across different outcome measures.

\section{Role of Self-Report and Voluntary Participation in QRIS}

While QRISs traditionally include some self-reported components (e.g., staff qualifications, director questionnaires) the degree to which a state QRIS relies on self-reporting varies (see Tout et al., 2010 for state-by-state specifics). QRISs for some states rely on selfreports for initial quality levels (e.g., in a 5-level program, levels 1-3 are self-report) with trained external assessors for higher levels (e.g., Iowa, Massachusetts, Michigan). In such programs, state agency staff verify the lower level self-report information (Lahti et al., 2015; Le et al., 2015), while external assessors report on higher level quality. When using self-report there is always a concern for potential respondent bias (Achenbach, McConaughy, \& Howell, 1987), particularly when quality rating is tied to funding, but to our knowledge, few states using selfreport have reported external validation studies, a gap this study aims to fill.

To encourage participation in QRISs, many states offer financial incentives, with tiered reimbursement rates that increase with the child care professional's rating level (Lugo-Gil et al., 2011). Grants for materials and supplies are also traditionally available through QRIS

participation (Hallam, Hooper, Bargreen, Buell, \& Han, 2017). The qualifications and incentive structures differ from state-to-state and can be tied to a variety of factors including the number of subsidized children served and adult-child ratio (Tout, Zaslow, Halle, \& Forry, 2009; Tout et al., 
2010). The self-report program discussed in this paper describes one state's approach to a QRIS, designed to achieve maximum buy-in from the state's childcare professionals, who played an active part in the development of the state's QRIS.

\section{Environmental Rating Scales and QRIS}

Environment Rating Scales are frequently used to rate quality in QRISs; the Compendium of Quality Rating Systems and Evaluations (Tout et al., 2010) reported that 23 out of the 25 QRISs they examined used the ECERS-R as an assessment of quality. However, the usefulness of ERS as a measure of child care quality is still being debated. A meta-analysis by Burchinal, Kainz, and Cai (2011) found that frequently used measures of classroom quality, such as the ECERS-R, are not always associated with specific child outcomes. These global quality scales may not concentrate enough on the individual processes proven to promote development (Lahti et al., 2015).

Researchers have suggested that ECERS-R scores might be overly influenced by the scoring procedure or embedded instrument design (Mathers, Linksey, Seddon \& Sylva, 2007; Zellman \& Perlman, 2008), and might underrepresent quality. For example, Zellman and Perlman (2008) reported concerns that true accuracy was not being reported since failure on the low-end of the scale prevented centers from being rated on indicators at the high-end of the scale. An alternative scoring issue with ERS is that even when the standard $85 \%$ agreement between raters is followed, which would be the difference between a center with a score of 3.5 and one with a score of 4.5 , that differential is enough to affect an overall program rating (Karoly et al., 2013). When a state's QRIS scores are linked to higher rates of subsidy reimbursement (Tout et al., 2010), this distinction in measurement accuracy can be significant (Norris \& Guss, 2016). 
Yet evidence has also shown that distinct components within ERS, the measures of global quality in the ECERS-R and of teacher-child interactions in the Classroom Assessment Scoring System (CLASS; Pianta, La Paro, \& Hamre, 2008), may in fact be associated with growth in specific child outcomes (Elicker, Langill, Ruprecht, Lewsader, \& Anderson, 2011; Sabol, Soliday Hong, Pianta, \& Burchinal, 2013). Katz (1994) defined the ERS perspective on quality as a "top-down" approach where environmental features deemed relevant by researchers are the foci for improvement. The alternative would be a "bottom-up" perspective where inferences about the child's subjective experience are the focus (Hallam, Fouts, Bargreen, \& Perkins, 2016).

\section{Utah's QRIS}

Utah had its first QRIS sub-committee meeting in September 2009 with a group consisting of two center director representatives, one family director representative, and eight members from the state office of child care (see Figure 1, Logic Model). Center directors were clear from the beginning that they opposed external assessors rating their centers' child care quality. Center directors typically have had significant influence in this state legislature, building on the legislature's preference for "grass-roots" input. Over the next eighteen months the committee reviewed and discussed available information on QRIS programs from other states, accreditation criteria for national organizations (e.g., National Association of Child Care Resource and Referral Agencies [NACCRRA] and the National Association for the Education of Young Children [NAEYC]), and rating scale criteria from the ECERS-R and CLASS. Personal opinions about childcare practices were also considered. Based on this information, a self-report, points-based system was developed titled "Care About Childcare" (CAC). CAC consists of six areas, inclusive of 120 individual indicators, and represents best practices for quality childcare. 
The CAC program was considered a Quality Recognition and Information System, rather than as a Quality Rating and Improvement System (Fronk, Gurko, \& Austin, 2013), thus reinforcing the position that this was a support system, not an assessment system. CAC addresses the five components typical of most QRISs (Tout, Chien, Rothenberg, \& Li, 2014). Three components remained unchanged from other QRISs (standards that define quality, quality improvement supports, and financial incentives), and two components were adapted by stakeholders to be specific to the preference of the state childcare professionals (a self-rated process without levels and dissemination of self-reported quality indicators to parents and consumers).

To claim a quality indicator, childcare professionals submit mandatory documentation indicating they have achieved the necessary requirements; documentation includes photos, written descriptions (e.g. lesson plans, program policies), or both. Personnel at local Child Care Resource and Referral agencies (CCR\&Rs: also called CACs to go along with the new CAC QRIS system) then examine these submissions to verify that requirements for the indicator were met. Verified indicators are posted on the CAC website so parents can compare participating centers and make informed decisions about the care they choose for their children. This strategy is commensurate with the QRIS logic model of Zellman and Perlman (2008) that views QRIS as an instrument of change through a market-driven strategy (Goffin \& Barnett, 2015). The assumption was that once parents are able to identify higher-quality centers, they will be less likely to use lower-quality programs (Jeon \& Buettner, 2015). Stakeholders hoped that although reporting indicators is voluntary, market competition would put pressure on childcare professionals to participate in the QRIS system and work to improve their quality to become a 
top choice center. For an overview of this program, including the way grants incentivize QRIS participation, see Figure 1, Logic Model.

Although Utah's QRIS program has been implemented statewide, questions remain regarding the validity of Utah]'s self-report program. In order to validate the CAC self-ratings on indicators, the state hired our team to compare self-reported quality indicators to external evaluator ratings on matching ECERS-R items. Because the legislature has expressed interest in the intersection of center childcare capacity and percentage of state subsidy clients with childcare quality, capacity and subsidy drove the sampling mechanism. As is typical in most "real-world" studies, the agency wanted a set of questions answered within a specific timeframe and did not support adding other measures to the design.

In addition to the problems of validity, it is unknown which types of indicators are more likely to be self-reported. Determining quality indicators most likely and less likely to be reported, will inform future work in the QRIS process.

\section{Research questions}

1. How do the centers compare on ECERS-R quality ratings and CAC quality ratings by subsidy level and capacity?

2. What are the characteristics of childcare centers, including capacity and subsidy level, for directors participating and not participating in a self-report QRIS?

3. Which subscales and items are most commonly reported and not reported in the CAC process?

4. Based on an independent measure of quality, how accurate is director self-report as an indicator of quality? 
5. How does quality compare between centers participating in CAC and those not participating?

\section{Methods}

\section{Participants}

This study took place in Utah, the $12^{\text {th }}$ largest state by land area in the United States with a population of 2.76 million. The latest census indicates that over $60 \%$ of the state's population resides within the counties included in the present study (U.S. Census Bureau, 2010). According to Care About Childcare (CAC) administration, at the time of this study (2014), there were 284 licensed, center-based child care programs. Two hundred fourteen (75\%) of these centers were located within the region used as the sampling pool for this study (L. Schilling, CAC Program Administrator, personal communication, March 24, 2017). While Utah centers generally enroll a mixture of children with state-subsidized and unsubsidized childcare on a first-come, first-served basis, some centers enroll very few subsidized children and sometimes none at all. Capacity, or the total number of children that could be enrolled at a center, was used as an indication of center size.

To create a representative sample, the median capacity for childcare centers ( 86 children) and median percentage of enrolled state-subsidized children at Utah centers (15.6\%) were used for a double-median split resulting in four equal sample strata: high capacity/high subsidy (HCHS), high capacity/low subsidy (HC-LS), low capacity/high subsidy (LC-HS), low capacity/low subsidy (LC-LS). Fifteen childcare centers were randomly selected within each of these resulting strata. Center directors served as the main point of contact throughout the study. If a director declined participation in this study, another center was randomly selected and invited to participate. Participation and refusal rates were nearly equal across strata (5-6 refusals each), 
with the exception of HC-LS centers, which had a refusal rate approximately twice as high as the others (12 refusals). The final sample for the study included 58 centers, four of which were university/college lab schools, and most were community-based for-profit. See Table 1 for characteristics of each group in this sample, stratified by capacity and subsidy.

\section{Measures}

Demographics. A demographic questionnaire, distributed electronically, was completed by directors. These surveys were later distributed as hard copy to increase response rates. The survey had 20 items, described below.

Education, training, and endorsements. Included in the director demographic survey were questions regarding director's education level, career ladder level, and whether or not they had earned a CDA certificate and/or state endorsements. Utah's career ladder system for directors, ranging from level one to ten, is based on the highest level of formal education obtained as well as in-service training. For example, level one requires basic training, while directors with a bachelor's degree or higher with at least 15 semester credits specific to early childhood are placed at level ten (Child Care Professional Development Institute, n.d.). State endorsements are earned when directors fulfill specific in-service training requirements designated by the state and can also boost a director career ladder level. Possible endorsements include: Infant and Toddler, School Readiness, Special Needs, Center Director's, Guidance and Emotional Wellness, School Age, Relationship Touchpoints, Theories and Best Practices, and Developing Your Child Care Business. In addition to education, training, and endorsements, the director survey asked questions regarding age and child care experience, both measured in years. Directors were also asked to indicate whether or not the center participated in the CAC/QRIS program. 
CAC participation or non-participation. Participation in CAC was defined as having one or more verified self-report CAC indicator (see details below). If there were no self-reported indicators, they were scored as "non-participating." Non-participating and participating centers were dummy-coded. Incentives were offered to participate in CAC; if centers reported they had achieved ten or more CAC indicators, they received a Welcome Grant, as indicated in Figure 1, Logic Model. Subsequently, Renewal Grants were earned by self-reporting on additional indicators.

\section{Center Quality.}

Care About Childcare (CAC) Quality Indicators. At the time of this study, there were 120 CAC self-report quality indicators divided into six areas as follows: Health and Safety (HS 22 indicators), Outdoor Environment (OE - 17), Indoor Environment (IE - 23), Family Involvement (FI - 17), Program (PR - 19), and Administration (AD - 22). In order to claim an indicator, programs were required to submit specific documentation in the form of photographs, center policy, lesson plans, training materials, inventories, parent materials, and written descriptions. Required documentation varied among indicators, ranging from one piece of supporting evidence to six pieces for a single indicator; several indicators also required separate documentation for each classroom within a center. Since local CACs managed the CAC/QRIS program, their staff reviewed documentation submitted within their region. After documentation was approved by local CACs, centers were allowed to post the indicators they had achieved online.

In this study, self-reported indicators that had been accepted by local CACs were compiled for each center. Indicators were scored as either yes (1) or no (0) to indicate whether or not they had been accepted. No externally rated reliability or validity information relating to 
the CAC indicators was available at the time of the study. Determining the validity of the selfreports was thus the primary research goal of this study.

Early Childhood Environment Rating Scale-Revised (ECERS-R; Harms et al., 2005). The ECERS-R was chosen to serve as a validation tool for the CAC quality indicators. The ECERS-R consists of seven subscales with a total of 43 items, each scored on a 7-point rating scale with clear descriptions for levels of 1 (inadequate), 3 (minimal), 5 (good), and 7 (excellent). Subscales include the following: Space and Furnishings (8 items), Personal Care Routines (6 items), Language-Reasoning (4 items), Activities (10 items), Interaction (5 items), Program Structure (4 items), and Parents and Staff (6 items). Administration consists of a direct classroom observation, lasting approximately three hours, followed by a brief interview with the classroom teacher, lasting twenty to thirty minutes. Internal consistency for subscales ranged from .71 to .88 , and for the instrument as a whole, internal consistency was .92 , supporting the use of both subscale and total scale scores for analyses (Harms et al., 2005).

ECERS-R to CAC Comparison. To facilitate comparison between the ECERS-R and CAC measures, indicators from each measure were "matched" and a dummy score created for each CAC indicator coded as "yes" (1) if all parallel ECERS-R indicators were observed and "no" (0) if the parallel indicator was not observed. The goal of this comparison was first, to use ECERS-R evidence as a validation for actual documentation submitted to CAC and second, to determine if the centers claimed as many CAC items as they were entitled to. In instances where programs did not claim a CAC indicator, ECERS-R evidence was used to show which indicators could have been claimed. For example, the CAC indicator "Program supports those children who need a rest time as well as those children who do not" (PR17) was coded as "yes" if the ECERS-R indicators "Nap/rest schedule is flexible to meet individual needs" (11.7.1) and 
"Provisions made for early risers and non-nappers" (11.7.2) were both observed; it was coded as "no" if neither ECERS-R indicator was observed.

To create the comparison, the ECERS-R state anchor (personally trained by instrument authors for statewide assessor reliability) and four ECERS-R researchers, child development graduate students trained by the state anchor, evaluated the CAC indicators to determine which indicators directly paralleled ECERS-R items. This comparison resulted in a shorter list (47 $\mathrm{CAC}$ indicators) containing only those $\mathrm{CAC}$ quality indicators that were directly evidenced through the ECERS-R items (Appendix A). The number of ECERS-R items varied, with some CAC indicators having one related ECERS item and others having multiple $(\max =6)$. A detailed breakdown for this comparison is found in Appendix B. This included 39\% of the CAC indicators, distributed as follows: 6 HS indicators (27\% of total); 5 OE indicators (29\%); 15 IE indicators, (65\%); 6 FI indicators (35\%), 10 PR indicators (53\%); and 5 AD indicators (23\%).

\section{Procedures}

Researchers called the selected center directors to explain the study and invite their participation. Upon verbal agreement, directors were electronically sent further details of the study, including informed consent and director surveys. At this time, a visit was also scheduled for a researcher to visit the center to conduct the ECERS-R assessment. In accordance with guidelines given by the funding agency (OCC) to access as many centers as possible, only one classroom per center was randomly selected for observation.

After directors agreed to participate in the study, arrangements were made for trained researchers to conduct ECERS-R observations and interviews. On the day of the visit, if forms had not previously been returned electronically, hard copies of the informed consent and surveys were provided at the beginning of the visit. Postage-paid envelopes were also provided for 
survey return. Child development graduate student researchers were trained to reliability by the state ECERS-R anchor. Reliability for this study meant achieving the same score or within one point of the same score as the state anchor, on $85 \%$ of the ECERS-R items for three consecutive observations. Reliability checks were conducted mid-way through the study to ensure that researchers were still meeting these guidelines. For remuneration, each teacher observed received fifty-dollars upon completion of the observation and interview.

\section{Results}

\section{Demographics}

Child care centers were included in this study without regard to their CAC participation. When data were analyzed, it was determined that twenty-nine of the centers $(50 \%)$ were participating in CAC while twenty-nine (50\%) were not. As a contrast, the 2014 statewide participation rate, when these data were collected, was 30\% (personal communication, Office of Child Care). Overall, center capacity ranged from 31 to 251 children while subsidy levels ranged from $0 \%$ to $158 \%$ (some centers had more than one child enrolled in a single "slot" resulting in percentages above 100). See Table 1 for a breakdown of capacity and subsidy by the four categories. Regarding education, less than half the sample had an associate degree or less (43.4\%), while just over half had achieved a career ladder level of $8(52.9 \%)$. In our sample, half the directors had worked in the childcare industry for less than twelve years $(50.9 \%)$.

\section{Question 1: What were the quality difference by ECERS-R and CAC indicators for capacity and subsidy ratings?}

To identify quality differences between centers with high capacity and those with low capacity, t-tests were run on ECERS-R subscales and total score and were found to be statistically non-significant. For differences by percentage of subsidized children, t-tests were 
run on ECERS-R subscale scores and significantly lower scores were found on every subscale and on overall score for centers with high subsidy (see Table 2). ECERS total scores were sorted by center subsidy and capacity, and a two-way ANOVA was run. There was not a statistically significant interaction for ECERS-R total score, $F(1,54)=.776, p=.382$, partial $\eta^{2}=.014$. When looking at the main effects, capacity was non-significant, $F(1,54)=.35, p=.56$, partial $\eta^{2}$ $=.006$, while there was a statistically significant difference in mean ECERS-R total score between centers with high and low subsidy, $F(1,54)=23.60, p<.001$, partial $\eta^{2}=.304$. For correlations between variables, see Table 3 .

Question 2: What are the characteristics of child care professionals participating in a selfreport QRIS compared with those that do not participate?

Demographic variables, including the director's age, education, years in child care, career ladder level, earning a CDA and/or a state endorsement, and center-level variables including capacity and subsidy rate, were analyzed to determine differences between child care directors voluntarily participating in CAC/QRIS and those that were not (Table 4). T-tests were run, and no significant differences were found between CAC participants and nonparticipants for age, education level, in-service training/certification, years of experience, and the subsidy and capacity level of the center.

\section{Question 3: Which subscales were most commonly reported in the CAC process?}

Since the CAC total score is based on point accumulation with all indicators equally weighted, the frequency with which an indicator was self-reported demonstrates which indicators contributed most often to the CAC rating. Subscale means were obtained by summing the number of times an indicator was claimed, divided by the number of indicators in the subscale. The subscale with the most self-reported indicators $(\mathrm{n}=29)$ was Health and Safety $(M=.23, S D$ 
$=.19)$, followed by Administration $(M=.20, S D=.19)$, Outdoor Environment $(M=.18, S D=$ .16), Family Involvement $(M=.17, S D=.17)$, Indoor Environment $(M=.16, S D=.17)$, and Program $(M=.13, S D=.16)$. Only two indicators were self-reported by more than half of the sample: HS4 (Soap and paper towels within reach; $M=.55, S D=.51$ ) and AD1 (Program has a signed contract with each family; $M=.52, S D=.51$ ). The eight CAC indicators most frequently self-reported required an average of 1.38 qualifying documents (i.e., photo, written documentation) for verification, while the eight indicators never self-reported averaged 3.75 (range: 2 to 6) qualifying documents required for verification.

\section{Question 4: Based on an independent measure of quality (ECERS-R), how accurate is director self-report as an indicator of quality?}

Analyses were conducted using the two CAC subscale scores: self-reported items and potential items or those items that could have been reported because they were validated by the external assessor using ECERS-R to CAC Comparison. First, paired t-tests were conducted; results suggested that center directors reported significantly fewer CAC indicators than they could have potentially claimed (see Table 5). Next, Cohen's Kappa was used to assess agreement on the 47 verifiable CAC indicators between self-reported and potential quality indicators, but because self-reported quality indicators were underreported, there was not a significant level of agreement. Finally, to further analyze the agreement and disagreement between the two CAC subscale scores (self-reported and potential), crosstabulations were run to provide counts of the number of indicators claimed and externally verified, unclaimed and but externally verified, and unclaimed and unverified, for all 47 verifiable CAC indicators. For the number of externally verified CAC quality indicators, to be claimed or unclaimed, see Table 6. For the number of CAC indicators claimed or unclaimed that were not externally verified, see 
Table 7. For external validation of self-reported CAC indicators, see Table 8 . Tables 6 , 7 , and 8 list the total number of indicators in that category by subscale and by total. Although they contain the same subscales, totals will vary based on category (i.e., verified [Table 6], unverified [Table 7], self-reported [Table 8]). For example, using Table 6 we see that for the 29 centers participating in CAC, there were a combined 54 indicators in the Health and Safety subscale that were externally verified using ECERS-R, but unclaimed. This happened $64.3 \%$ of the time suggesting considerable underreporting.

Overall, for the 29 centers participating in CAC, only $21 \%$ of 709 (overall total of all externally verified indicators for all subscales) potential CAC quality indicators, as verified through external validation, were actually claimed (Table 6). Of these, the subscale with the highest percentage of claimed indicators was Health and Safety $(35.7 \%$ of 84 potential indicators), followed by Outdoor Environment (23.2\% of 69), Family Involvement (22.9\% of 83), Program (18.3\% of 142), Indoor Environment (17.7\% of 249), and Administration (17.1\% of 82). A large majority of the quality indicators that were not validated were also unclaimed (85.1\% of 646 unvalidated indicators; Table 7), suggesting these were harder to claim and/or verify, or were aspects of quality centers had not addressed in a measurable way.

For the CAC indicators that were self-reported (claimed), $61.3 \%$ of 243 (overall selfreported total for all subscales) self-reported quality indicators for the 29 participating centers were externally verified, with $38.7 \%$ unverified (see Table 8 ). The CAC subscale with the highest percentage verified was Indoor Environment (72.1\% of 61 indicators), followed by Family Involvement (65.5\% of 29), Administration (63.6\% of 22), Program (61.9\% of 42 indicators), Health and Safety (51.7\% of 58), and Outdoor Environment (51.6\% of 31). 
Correlations were run between the two CAC subscale scores, i.e., self-reported or claimed items and potential subscale scores as determined through external validation. None were significant, potentially due to high percentage of under-reported items. For centers that reported more than the mean number of indicators $(M=19.83, S D=14.29)$, only the Family Involvement subscale scores (self-reported score and externally validated score) correlated $(r=$ $.63, p<.05, n=12$ ), indicating some evidence that CAC was a valid report of quality for centers that self-reported more indicators.

\section{Question 5: How does quality compare between centers participating in CAC and those}

\section{that do not?}

To look for differences in quality between centers participating in CAC and those that do not participate, t-tests were run on the seven ECERS-R subscales and total score, and were found to be non-significant (think about putting the score and degree of freedom here, even though it is NS) indicating that participation in the QRIS was not directly related to higher quality of care.

\section{Discussion}

In an effort to improve the quality of child care in a state or region, QRISs have been developed across the United States and have been commissioned with a variety of directives (Lahti et al., 2015). While there is no uniform approach in the design and implementation of a QRIS, nor a universal definition of quality, the primary goal is the incremental improvement of child care with ratings provided to help inform parents of quality (Goffin \& Barnett, 2015). The purpose of this paper is to evaluate one state's approach in designing and implementing a voluntary, self-report QRIS.

Question 1: What were the quality difference by ECERS-R and CAC indicators for capacity and subsidy ratings? 
Because the efforts were made to recruit a sample representative of centers with both high and low capacity and subsidy, analyses initially looked at differences for the four strata (HC-HS, HC-LS, LC-HS, and LC-HS). Our research found that center capacity was not significantly related to ECERS-R scores in our sample. On the other hand, the study provides support for past research (e.g., Jones-Branch, Torquati, Raikes, \& Edwards, 2004) indicating that the quality of child care is negatively influenced by the percentage of subsidized children in a center. As our data indicate, ECERS-R scores in high subsidy centers were significant lower on every subscale and on the overall score. Further, the range of mean subscale scores, 2.48-3.70 on a 7-point scale, indicate overall average quality ranges from poor to minimally acceptable.

\section{Question 2: What are the characteristics of child care professionals participating in a self-} report QRIS compared with those that do not participate?

In our sample we found that there were no significant differences in age, experience, and state in-service training between center directors that chose to participate in CAC and those that chose not to participate, which as far as we are aware has not been reported previously. However, because of missing educational data for some CAC nonparticipants, there may have been actual differences that we were unable to identify.

\section{Question 3: Which subscales were most commonly reported in the CAC process?}

When evaluating the frequency with which CAC indicators were self-reported, results suggest that those easiest to report are most often claimed; that is, reporting is made easier when all that is required is a simple photo and nothing more complex such as submission of lesson plans and photos of children and teachers involved in different lesson activities. Among our sample of CAC participants, $79 \%$ of externally verified quality indicators were not self-reported (see Table 6), suggesting the perceived benefit was not worth the process to claim existing 
quality. This suggests that for our sample, a self-report QRIS of this nature resulted in few changes in quality and was rather an indicator of the easiest to report preexisting quality conditions and procedures.

\section{Question 4: Based on an independent measure of quality, how accurate is director self- report as an indicator of quality?}

Our results suggest that in a self-report QRIS, unless participation is strongly incentivized, even existing quality indicators will go unclaimed: especially indicators with complex or time intensive validation. This is demonstrated through a comparison between the ECERS-R subscale with the highest percentage of unclaimed but verified quality indicators (Indoor Environment; 82.3\% unclaimed) and the lowest (Health and Safety; 64.3\% unclaimed). To claim quality indicators in the Indoor Environment subscale, 90\% require verification for each classroom in a center, compared to $25 \%$ of the quality indicators in the Health and Safety subscale. The external ratings of quality, compared to self-report, were significantly higher for all CAC subscales, in part because of how frequently items went unreported. The threshold to receive a welcome grant was 10 quality indicators and for a renewal grant 5-10 additional indicators (see Figure 1). Those participating in CAC did the minimal and were much more likely to underreport quality than over report.

In addition, $85.1 \%$ of all quality indicators across the 29 centers in our study were not self-reported for those participating in CAC or externally validated by assessors. These indicators may be harder to verify for the CAC participants or represent aspects of quality that the centers had not addressed because of cost or complexity. Likely for the CAC participants, the qualifying documentation should be simplified. Thus, for the sample surveyed, there is substantial room for quality improvement. Further, a voluntary self-report QRIS structured as 
this one was, seems unlikely to drive quality improvements very effectively (Zellman \& Karoly, 2012).

Although centers frequently under-reported quality (79\% of verified), they also overreported in some cases as $38.7 \%$ of indicators that were claimed through self-report were not validated though external review. Thus, the self-report process does not always capture quality accurately. However, when looking at centers that claimed more than the mean number of CAC indicators, the CAC to ECERS-R Comparison showed some evidence of validity, particularly for the Family Involvement subscale. There is evidence then that at least for this sample, directors claiming more CAC indicators than the majority of centers in this study, were more accurate in their claims as verified by external assessors. Perhaps this implies that although a self-report system does not work for the majority of centers, those directors who are the most conscientious reporters in terms of quantity of indicators reported, also are more accurate as verified by external assessment.

\section{Question 5: How does quality compare between centers participating in CAC and those}

\section{that do not?}

When quality was compared between centers participating in CAC and those not participating, no significant differences were found on the ECERS-R subscale and total scores. One of the primary goals of QRISs across the country is to improve the quality of child care (Lahti et al., 2015), but in this case, the CAC self-report system failed to differentiate those who participated in the system versus those who did not. To put it another way, our results suggest that participation in a voluntary self-report QRIS of this nature did not make a statistically significant difference in child care quality.

\section{Implications}


While participating in the self-report CAC does not appear to improve quality, CAC has fulfilled some QRIS responsibilities. CAC defined quality standards, provided financial incentives for quality improvement, offered training to childcare professionals, and informed parents of participants' self-reported quality. However, active CAC participation was minimal, with the reported items limited to the indicators easiest to report, while other quality items went unreported. Further, for the most part, directors seemed to report only enough items to pass minimal standards. Anecdotal evidence based on conversations with directors suggested that the reporting process was time and labor intensive making additional work beyond the minimum requirements unappealing. Finally, while a number of centers could have claimed more quality indicators than they actually did, this was not done and what was claimed was not completely valid.

\section{Limitations and Strengths}

Our study is not without limitations but represents the compromises that often must be made in limited resources, real-world studies. For example, sample participants were limited to center-based care, excluding other types of care such as family childcare, family group care, and stand-alone preschools. In order to conserve resources, the funding agency preferred that only one classroom per center be included in the study. Other research has suggested that alternative sampling methods may be more appropriate, such as including more than one classroom per center to measure variations in quality within the center (e.g., West, Tarullo, Aikens, Malone, \& Carlson, 2011) and measuring child outcomes as well. The state's purpose though, was to include as many centers as possible within the sample parameters and to look specifically at subsidy and capacity. The low study size, particularly for directors participating in CAC, could be a drawback; however, when considering the number of CAC participants across the state and 
the low population of the state, programs participating in CAC were actually over-sampled in this study, providing a better glimpse of a self-report system than might otherwise have been obtained. The uniqueness of this state's QRIS with regard to voluntary participation and the element of self-report, may also limit generalizability. On the other hand, this study provides insight into elements that were not as impactful as one might assume in a self-report system. For example, director age, experience, and education did not contribute to higher participations rates, a finding that requires further attention in future studies of self-report systems. Future studies would be wise to include qualitative interviews with teachers and administrators to better understand these issues in ways a survey might not address.

The CAC to ECERS-R comparison provided data prohibitive of advanced statistical analyses. Our data were mostly dichotomous (e.g., self-reported indicator: yes/no; externally verified indicator: yes/no; etc.) limiting the depth of the investigation. A richer coding system could have yielded a more thorough understanding of a self-report QRIS. We clearly need to understand more about a self-report system before we can argue that it is always effective in promoting childcare quality. 
Acknowledgments: We thank the State Office of Childcare for its support of this work. Thank you to the directors and providers who participated in data collection.

Declaration of Interest Statement: No potential conflict of interest was reported by the authors. 


\section{References}

Achenbach, T. M., McConaughy, S. H., \& Howell, C. T. (1987). Child/adolescent behavioral and emotional problems: Implications of cross-informant correlations for situational specificity. Psychological Bulletin, 101(2), 213-232. doi:10.1037/0033-2909.101.2.213

Boller, K., \& Maxwell, K. (2015). QRIS research: Looking back and looking forward. Early Childhood Research Quarterly, 30, 339-342. doi:10.1016/j.ecresq.2014.10.002

Boller, K., Paulsell, D., Del Grosso, P., Blair, R., Lundquist, E., Kassow, D. Z., \& Raikes, A. (2015). Impacts of a child care quality rating and improvement system on child care quality. Early Childhood Research Quarterly, 30, 306-315. doi:10.1016/j.ecresq.2014.10.001

Burchinal, M. R., Kainz, K., \& Cai, Y. (2011). How well do our measures of quality predict child outcomes? A meta-analysis and coordinated analysis of data from large scale studies of early childhood settings. In M. Zaslow, I. Martinez-Beck, K. Tout, \& T. Halle (Eds.), Quality measurement in early childhood settings (pp. 11-27). Baltimore, MD: Paul H. Brookes.

Burchinal, M. R., Vandergrift, N., Pianta, R., \& Mashburn, A. J. (2010). Threshold analysis of association between child care quality and child outcomes for low-income children in prekindergarten programs. Early Childhood Research Quarterly, 25(2), 166-176. doi:10.1016/j.ecresq.2009.10.004

Child Care Professional Development Institute (CCPDI) (n.d.). Professional development system. Retrieved from https://ccpdi.usu.edu/index.

Cochran, M. (2007). Finding our way: The future of American early care and education. Washington, DC: Zero to Three. 
Elicker, J., Langill, C., Ruprecht, K., Lewsader, J., \& Anderson, T. (2011). Evaluation of paths to QUALITY. Indiana's Child Care Quality Rating and Improvement System: Final report (Technical Report \#3). West Lafayette, IN: Purdue University.

Fronk, A., Gurko, K., \& Austin, A. M. B. (2013). White Paper \#1: Implementation, Introduction, and Methods. Family, Consumer, and Human Development Faculty Publications. Retrieved from http://digitalcommons.usu.edu/fchd_facpub/673.

Fuller, B., Loeb, S., Kagan, S. L., \& Carrol, B. (2004). Child care in poor communities: Early learning effects of type. Quality, and Stability. Child Development, 75(1), 47-65. doi:10.1111/j.1467-8624.2004.00653.x

Goffin, S. G., \& Barnett, W. S. (2015). Assessing QRIS as a change agent. Early Childhood Research Quarterly, 30, 179-182. doi:10.1016/j.ecresq.2014.08.005

Gordon, R. A., Hofer, K. G., Fujimoto, K. A., Risk, N., Kaestner, R., \& Korenman, S. (2015). Identifying high-quality preschool programs: New evidence on the validity of the early childhood environment rating scale-revised (ECERS-R) in relation to school readiness goals. Early Education and Development, 26(8), 1086-1110. doi:10.1080/10409289.2015.1036348

Hallam, R. A., Fouts, H. N., Bargreen, K. N., \& Perkins, K. (2016). Teacher-child interactions during mealtimes: Observations of toddlers in high subsidy child care settings. Early Childhood Education Journal, 44, 51-59. doi:10.1007/s10643-014-0678-x

Hallam, R., Hooper, A., Bargreen, K., Buell, M., \& Han, M. (2017). A two-state study of family child care engagement in quality rating and improvement systems: A mixed-methods analysis. Early Education and Development, 1-15. doi:10.1080/10409289.2017.1303306 
Harms, T., Clifford, R., \& Cryer, D. (2005). Early childhood environmental rating scalerevised. New York, NY: Columbia University Teachers College Press.

Jeon, L., \& Buettner, C. (2015). Quality rating and improvement systems and children's cognitive development. Child \& Youth Care Forum, 44, 191-207. doi:10.1007/s10566014-9277-7

Jones-Branch, J. A., Torquati, J. C., Raikes, H., \& Edwards, C. (2004). Child care subsidy and quality. Early Education and Development, 15(3), 329-341. doi:10.1207/s15566935eed1503_5

Karoly, L. A., Zellman, G. L., \& Perlman, M. (2013). Understanding variation in classroom quality within early childhood centers: Evidence from Colorado's quality rating and improvement system. Early Childhood Research Quarterly, 28(4), 645-657. doi:10.1016/j.ecresq.2013.05.001

Katz, L. G. (1994). Perspectives on the quality of early childhood programs. Phi Delta Kappan, 76(3), 200-205. Retrieved from: http://www.jstor.org/stable/20405296

Lahti, M., Elicker, J., Zellman, G., \& Fiene, R. (2015). Approaches to validating child care quality rating and improvement systems (QRIS): Results from two states with similar QRIS type designs. Early Childhood Research Quarterly, 30, 280-290. doi:10.1016/j.ecresq.2014.04.005

Le, V. N., Schaack, D. D., \& Setodji, C. M. (2015). Identifying baseline and ceiling thresholds within the Qualistar early learning quality rating and improvement system. Early Childhood Research Quarterly, 30, 215-226. doi:10.1016/j.ecresq.2014.03.003

Lugo-Gil, J., Sattar, S., Ross, C., Boller, K., Tout, K., \& Kirby, G. (2011). The quality rating and improvement system (QRIS) evaluation toolkit (OPRE Report No. 2011-31). 
Washington, DC: U.S. Department of Health and Human Services, Administration for Children and Families, Office of Planning, Research and Evaluation. Retrieved from https://www.mathematica-mpr.com//media/publications/pdfs/earlychildhood/qris_toolkit.pdf

Mathers, S., Linksey, F., Seddon, J., \& Sylva, K. (2007). Using quality rating scales for professional development: Experiences from the UK. International Journal of Early Years Education, 15, 261-274. doi:10.1080/09669760701516959

Mitchell, A. W. (2009). Quality rating and improvement systems as the frame-work for early care and education system reform. Retrieved from http://www. buildinitiative.org/files/QRIS-Framework.pdf

Norris, D. J., \& Guss, S. (2016). Low quality of basic caregiving environments in child care: Actual reality or artifact of scoring?. Journal of Research in Childhood Education, 30(4), 513-528. doi:10.1080/02568543.2016.1215358

Paulsell, D., Tout, K., \& Maxwell, K. (2013). Evaluating implementation of Quality Rating and Improvement Systems. In T. Halle, A. Metz, \& I. Martinez-Beck (Eds.), Applying implementation science in early childhood programs and systems (pp. 269-293). Baltimore, MD: Paul H. Brookes.

Pianta, R. C., La Paro, K. M., \& Hamre, B. K. (2008). Classroom assessment scoring system manual, Pre-K. Baltimore, MD: Paul H. Brookes.

QRIS National Learning Network. (2017). QRIS state contacts, QRIS national learning network. Retrieved from http://qrisnetwork.org/qris-state-contacts-map 
Sabol, T., Soliday Hong, S., Pianta, R., \& Burchinal, M. (2013). Can rating pre-k programs predict children's learning? Science, 341, 845-846. Retrieved from http://www.sciencemag.org/

Smith, S., Dong, X., Stephens, S. A., \& Tout, K. (2017). How studies of QRIS measure quality improvement activities: An analysis of measures of training and technical assistance. New York: Child Care \& Early Education Research Connections. Retrieved from http://www.nccp.org/publications/pub_1189.html

Tout, K., Chien, N., Rothenberg, L., \& Li, W. (2014). Implications of QRIS design for the distribution of program ratings and linkages between ratings and observed quality. Washington, DC: Office of Planning, Research and Evaluation, Administration for Children and Families, U.S. Department of Health and Human Services. Retrieved from http://files.eric.ed.gov/fulltext/ED566252.pdf

Tout, K., Starr, R., Soli, M., Moodie, S., Kirby, G., \& Boller, K. (2010). Compendium of quality rating systems and evaluations. Washington, DC: Administration for Children and Families, Department of Health and Human Services, Mathematical Policy Research, Inc., and Child Trends. Retrieved from http://www.acf.hhs.gov/programs/opre/resource/compendium-of-quality-rating-systemsand-evaluations

Tout, K., Zaslow, M., Halle, T., \& Forry, N. (2009). Issues for the next decade of quality rating and improvement systems. Retrieved from http://www.childtrends.org/Files/Child_Trends-2009_5_19_RB_QualityRating.pdf U.S. Census Bureau (2010). Quick Facts. Retrieved from https://www.census.gov/quickfacts/. 
West, J., Tarullo, L., Aikens, N., Malone, L., and Carlson, B. L. (2011). FACES 2009 Study Design. OPRE Report 2011-9. Washington, DC: Office of Planning, Research and Evaluation, Administration for Children and Families, U.S. Department of Health and Human Services.

Zaslow, M., Burchinal, M., Tarullo, L., \& Martinez-Beck, I. (2016). V. Quality thresholds, features, and dosage in early care and education: Discussion and conclusions. Monographs of the Society for Research in Child Development, 81, 75-87. doi: $10.1111 /$ mono. 12240

Zellman, G. L., \& Karoly, L. (2012). Approaches to incorporating child assessments into early childhood quality rating and improvement systems. Santa Monica, CA: The RAND Corporation. Retrieved from http://www.rand.org/pubs/research_briefs/RB9639/index1.html

Zellman, G. L., \& Karoly, L. A. (2015). Improving QRISs through the use of existing data: A virtual pilot of the California QRIS. Early Childhood Research Quarterly, 30, 241-254. doi:10.1016/j.ecresq.2014.04.006

Zellman, G. L., \& Perlman, M. (2008). Child-care quality rating and improvement systems in five pioneer states (RAND Monograph No. MG-795). Santa Monica, CA: RAND Corporation. Retrieved from http://www.rand.org/pubs/monographs/MG795.html?doc=MG-795-AECF/SPF/UWA 


\section{Appendices}

Appendix A.

List of CAC Quality Indicators Matched to ECERS-R Items by Subscale

Indicator Indicator Description

\section{Health and Safety}

HS 3 Staff and children wash hands upon arrival and when re-entering the program or classroom

HS 4 Soap and paper towels in program are at child height

HS 7 Outdoor activity time is scheduled daily for at least 60 minutes

HS 8 Television, video and computer use by children is limited

HS 9 Children do not watch television or videos or play non-educational computer games

HS 20 Program has a procedure for cleaning up bodily fluids

Outdoor Environment

OE 2 Each child is able to use portable play equipment daily

OE 3 A playhouse and props for dramatic play are available on each playground

OE 6 At least $1 / 3$ of each play area is covered in natural material

OE 14 Program has a stationary play structure on each playground used by preschool and school age children

OE 15 School-age children have daily access to a variety of portable large motor materials that are appropriate for them

\section{Indoor Environment}

IE 1 Each classroom offers at least 3 different activity/learning centers that are accessible simultaneously throughout the day

IE 2 Each classroom offers an additional two or more activity/learning centers that are accessible simultaneously throughout the day

IE 3 Activity/learning centers are available at least two hours a day

IE 4 Activity/learning centers are available for an additional one or two hours per day

IE 5 Each room has additional materials available to enrich centers and maintain interest

IE 6 Each classroom has a cozy area available to the children throughout the day

IE 9 The room arrangement protects children using the learning centers from interruptions

IE 10 There is an individual storage space for each child's belongings

IE 11 Space is set aside to allow one or two children to play undisturbed by others

IE 12 There is indoor space for active physical play

IE 13 Tables and chairs are child height

IE 15 Each room has natural lighting that can be controlled

IE 16 The program uses sound reducing materials in classrooms to reduce the noise level

IE 20 Pictures are displayed at child eye level and some are changed quarterly

IE 21 Children's art is displayed at children's eye level

\section{Family Involvement}

FI 1 Families are invited to spend time with their child at the program prior to enrollment

FI 5 Family conferences are held at least twice a year

FI 6 Program provides opportunity for families to share knowledge about their children 
FI 13 Families receive monthly information from and about the program through written newsletters or social media

FI 15 Families are involved in the planning of activities and/or menu options

FI 17 Families who do not speak the same language as the caregiver are able to share their language with the child care program

\section{Program}

PR 1 The program has predictable but flexible daily schedule that encourages purposeful play and shows that the majority of the day is child directed

PR 2 Schedule shows a balance of active and quiet activities

PR 3 The program schedules time to interact with children in small groups or individually

PR 4 Transition activities are used to facilitate smooth changes between activities

PR 8 Activities that support children's physical development are provided daily

PR 9 The program promotes children's cognitive development by offering daily opportunities to explore math and science concepts

PR 16 Caregivers sit with and interact with children during meals and snacks

PR 17 Program supports those children who need a rest time as well as those children who do not

PR 18 Program has a plan in place to accommodate children with special needs who may wish to enroll

PR 19 The program has at least 25 professional sources of information (books and/or professional articles) on child development and early care and education that address all of the age groups served
Administration
AD 6 Program is reviewed annually by parents
AD 13 Internal training opportunities go beyond topics required by licensing
AD 14 Annual staff evaluations are completed
AD 17 Monthly staff meetings that include staff development activities
AD 20 The program offers financial incentives for increased education 
Appendix B.

Details for Comparison of CAC Quality Indicators and ECERS-R Items

\begin{tabular}{|c|c|c|c|}
\hline $\begin{array}{l}\mathrm{CAC} \\
\text { Indicator }\end{array}$ & Parallel ECERS-R Item(s) & $\begin{array}{l}\mathrm{CAC} \\
\text { Indicator }\end{array}$ & Parallel ECERS-R Item(s) \\
\hline HS3 & $13.1 .1,13.3 .1$ & IE20 & $6.5 .1,6.5 .3$ \\
\hline HS4 & 12.5.2 & IE21 & $6.3 .2,6.5 .3$ \\
\hline HS7 & $34.3 .3,35.3 .1,35.5 .1,7.3 .1$ & FI1 & 38.5 .1 \\
\hline HS8 & 27.3.3, OR $27 \mathrm{NA}$ & FI5 & 38.5 .3 \\
\hline HS9 & $27 \mathrm{NA}$ & FI6 & 38.5 .3 \\
\hline HS20 & 14.3 .3 & FI17 & 38.5 .4 \\
\hline OE2 & $8.5 .1,8.7 .1$ & FI13 & 38.5 .3 \\
\hline OE3 & 24.7 .3 & FI15 & $10.5 .4,38.7 .3$ \\
\hline OE6 & 7.7 .1 & PR1 & $34.3 .1,34.5 .1,36.7 .1$ \\
\hline OE14 & 8.7 .1 & PR2 & 35.5 .1 \\
\hline OE15 & 8.3.3, 8.5.1, 8.5.2, 8.7.1 & PR3 & 36.5 .2 \\
\hline IE1 & 4.5 .1 & PR4 & $34.5 .4,34.7 .1$ \\
\hline IE2 & 4.7 .1 & PR8 & 7.3.1, 8.3.1, 34.3.3, 193.1 \\
\hline IE3 & 4.5.1, 35.5.1 (if program > $6 \mathrm{hrs)}$ & PR9 & $\begin{array}{l}\text { 17.3.1, 25.3.1, 25.3.2, 26.3.1, } \\
\text { 26.3.2, 26.5.4 }\end{array}$ \\
\hline IE4 & 4.5.1, 35.5.1 (if program $>6 \mathrm{hrs)}$ & PR16 & 10.5 .1 \\
\hline IE5 & 4.7.3, 35.7.2 & PR17 & $11.7 .1,11.7 .2$ \\
\hline IE6 & 3.5 .1 & PR18 & 5 or higher on 37 \\
\hline IE9 & 4.5 .3 & PR19 & 43.5 .3 \\
\hline IE10 & 2.3 .1 & AD6 & 38.7 .1 \\
\hline IE11 & 5.5 .1 & AD13 & 43.5 .2 \\
\hline IE12 & 7.5.1 & AD14 & 42.5 .2 \\
\hline IE13 & 2.5 .1 & AD17 & 43.5 .3 \\
\hline IE15 & $1.5 .2,1.7 .2$ & AD20 & 43.7 .1 \\
\hline IE 16 & 1.3 .2 & & \\
\hline
\end{tabular}




\section{Tables}

Table 1

Mean Capacity and Subsidy by Category

\begin{tabular}{lccc}
\hline & & $\begin{array}{c}\text { Mean Capacity \# of Children }(S D) \\
\text { Min/Max }\end{array}$ & $\begin{array}{c}\text { Mean Subsidy \% (SD) } \\
\text { Min/Max }\end{array}$ \\
\hline High Capacity/ & \multirow{2}{*}{15} & $158(48)$ & $40(25)$ \\
High Subsidy & & $100 / 251$ & $16 / 104^{*}$ \\
High Capacity/ & \multirow{2}{*}{14} & $129(34)$ & $7(6)$ \\
Low Subsidy & & $90 / 215$ & $0 / 17$ \\
Low Capacity/ & 14 & $65(15)$ & $62(41)$ \\
High Subsidy & & $33 / 86$ & $17 / 158^{*}$ \\
Low Capacity/ & \multirow{2}{*}{15} & $63(15)$ & $4(5)$ \\
Low Subsidy & & $31 / 83$ & $0 / 14$ \\
\hline
\end{tabular}

"Some centers have more than one child enrolled in a single "slot", resulting in maximum percentages above 100 
Table 2

Differences on ECERS-R Subscale Scores Between Centers with High and Low Subsidy

\begin{tabular}{lcccc} 
& High Subsidy $n=30$ & & Low Subsidy $n=28$ & \\
\cline { 2 - 2 } \cline { 5 - 5 } & Mean $(S D)$ & & Mean $(S D)$ & \\
\cline { 2 - 2 } Space and Furnishings & $3.45(.83)$ & & $4.23(.84)$ & $3.54^{* * *}$ \\
Personal Care Routines & $2.48(.70)$ & & $3.24(.97)$ & $3.43^{* * *}$ \\
Language-Reasoning & $2.90(.81)$ & & $3.70(.93)$ & $3.47^{* * *}$ \\
Activities & $2.76(.65)$ & & $3.42(.78)$ & $3.53^{* * *}$ \\
Interaction & $3.65(1.17)$ & & $4.51(1.14)$ & $2.84^{* *}$ \\
Program Structure & $3.70(1.15)$ & & $4.35(1.05)$ & $2.23^{*}$ \\
Parents and Staff & $3.63(.59)$ & & $4.49(.74)$ & $4.95^{* * *}$ \\
Total Score & $3.13(.62)$ & & $3.90(.58)$ & $4.87^{* * *}$ \\
\hline
\end{tabular}

Note. Sample split at median percentage of capacity that is subsidy children, resulting in high and low subsidy groups. Each t-test has 56 degrees of freedom.

${ }^{*} p \leq .05, \stackrel{* *}{p} \leq .01,{ }^{* * *} p \leq .001$ 
Table 3

Correlations between ECERS-R Subscale Scores, Director Demographics, and CAC Participation

\begin{tabular}{|c|c|c|c|c|c|c|c|c|c|c|c|c|c|c|c|c|}
\hline & 1 & 2 & 3 & 4 & 5 & 6 & 7 & 8 & 9 & 10 & 11 & 12 & 13 & 14 & 15 & 16 \\
\hline $\begin{array}{l}\text { 1. Space and } \\
\text { Furnishing }\end{array}$ & $\begin{array}{ll}-- \\
\end{array}$ & & & & & & & & & & & & & & & \\
\hline $\begin{array}{l}\text { 2. Personal } \\
\text { Care }\end{array}$ & $.49^{\mathrm{a}}$ & --- & & & & & & & & & & & & & & \\
\hline $\begin{array}{l}\text { 3. Language- } \\
\text { Reasoning }\end{array}$ & $.52^{\mathrm{a}}$ & $.44^{\mathrm{a}}$ & --- & & & & & & & & & & & & & \\
\hline 4. Activities & $.67^{\mathrm{a}}$ & $.37^{\mathrm{b}}$ & $.52^{\mathrm{a}}$ & --- & & & & & & & & & & & & \\
\hline 5. Interaction & $.56^{\mathrm{a}}$ & $.53^{\mathrm{a}}$ & $.72^{\mathrm{a}}$ & $.40^{\mathrm{b}}$ & --- & & & & & & & & & & & \\
\hline $\begin{array}{l}\text { 6. Program } \\
\text { Structure }\end{array}$ & $.66^{\mathrm{a}}$ & $.36^{\mathrm{b}}$ & $.47^{\mathrm{a}}$ & $.48^{\mathrm{a}}$ & $.56^{\mathrm{a}}$ & --- & & & & & & & & & & \\
\hline $\begin{array}{l}\text { 7. Parents and } \\
\text { Staff }\end{array}$ & $.47^{\mathrm{a}}$ & $.34^{\mathrm{b}}$ & $.28^{\mathrm{c}}$ & $.39^{\mathrm{b}}$ & .26 & $.36^{\mathrm{b}}$ & --- & & & & & & & & & \\
\hline $\begin{array}{l}\text { 8. Subsidy } \\
\text { percentage }\end{array}$ & $-.36^{\mathrm{b}}$ & $-.32^{\mathrm{c}}$ & $-.43^{\mathrm{a}}$ & $-.40^{\mathrm{b}}$ & -.22 & -.22 & $-.63^{\mathrm{a}}$ & --- & & & & & & & & \\
\hline $\begin{array}{l}\text { 9. Center } \\
\text { capacity }\end{array}$ & .20 & -.23 & -.09 & .09 & -.12 & .13 & -.05 & -.04 & --- & & & & & & & \\
\hline $\begin{array}{l}\text { 10. Director } \\
\text { experience }\end{array}$ & .16 & .05 & $.35^{\mathrm{b}}$ & .20 & .19 & .18 & .04 & -.19 & -.10 & --- & & & & & & \\
\hline $\begin{array}{l}\text { 11. Director } \\
\text { Age }\end{array}$ & -.11 & -.15 & $.31^{\mathrm{c}}$ & .10 & .06 & -.04 & -.06 & -.10 & .01 & $.54^{\mathrm{a}}$ & --- & & & & & \\
\hline $\begin{array}{l}\text { 12. Career } \\
\text { ladder }\end{array}$ & .24 & .09 & .13 & .26 & .09 & .14 & .09 & -.05 & -.01 & .24 & .14 & --- & & & & \\
\hline $\begin{array}{l}\text { 13. Education } \\
\text { level }\end{array}$ & $.35^{\mathrm{b}}$ & .02 & .21 & .24 & .18 & .21 & $.30^{\mathrm{c}}$ & -.17 & -.05 & $.34^{\mathrm{c}}$ & .11 & $.32^{\mathrm{c}}$ & --- & & & \\
\hline 14. CDA & .15 & .07 & .13 & $.37^{\mathrm{b}}$ & .06 & .10 & -.05 & .03 & -.06 & .15 & -.06 & .16 & -.11 & --- & & \\
\hline $\begin{array}{l}\text { 15. State } \\
\text { Endrsmnts }\end{array}$ & .02 & .04 & -.02 & .12 & -.10 & .16 & -.17 & .11 & .17 & .10 & .15 & .20 & $-.31^{\mathrm{c}}$ & .13 & --- & \\
\hline 16. CAC & .20 & .12 & .00 & .12 & .11 & .18 & .16 & -.18 & -.00 & -.04 & -.07 & .17 & $.29^{c}$ & -.06 & -.10 & --- \\
\hline
\end{tabular}


Table 4

Demographic Data for QRIS Participants and Nonparticipants

\begin{tabular}{|c|c|c|c|c|c|c|}
\hline \multirow[b]{2}{*}{ Variable } & \multicolumn{3}{|c|}{$\begin{array}{l}\text { QRIS Participants } \\
(\mathrm{n}=29)\end{array}$} & \multicolumn{3}{|c|}{$\begin{array}{l}\text { QRIS Nonparticipants } \\
(\mathrm{n}=29)\end{array}$} \\
\hline & $\%$ & $\mathrm{M}(\mathrm{SD})$ & $\mathrm{n}$ & $\%$ & $\mathrm{M}(\mathrm{SD})$ & $\mathrm{n}$ \\
\hline Age & & $40.1(11.2)$ & 28 & & $41.6(11.5)$ & 29 \\
\hline Highest level of education & & & 22 & & & 16 \\
\hline High school/GED & 25 & & & 12.5 & & \\
\hline Some college credits & 12.5 & & & 43.8 & & \\
\hline Associate degree & 12.5 & & & 12.5 & & \\
\hline Bachelor's degree & 29.2 & & & 31.3 & & \\
\hline Graduate degree & 12.5 & & & 0 & & \\
\hline Other & 8.3 & & & 0 & & \\
\hline Training/Certification & & & 28 & & & 25 \\
\hline CDA & 50 & & & 56 & & \\
\hline State endorsements & 50 & & & 60 & & \\
\hline Career Ladder & & $6.9(3.4)$ & & & $5.6(3.8)$ & \\
\hline Years of experience & & $12.1(8.1)$ & 28 & & $12.8(8.4)$ & 27 \\
\hline Receiving a subsidy & 22 & & & 33.7 & & \\
\hline Center capacity & & $104.0(49.8)$ & & & $104.3(54.3)$ & \\
\hline
\end{tabular}

Note. Means and frequencies are based on the $N$ for each variable. Capacity is measured as number of children; subsidy is measured as a percentage of capacity. 
Table 5

Paired T-Tests Examining Differences Between External Ratings and Self-Reported Ratings of CAC subscales

\begin{tabular}{lcccc}
\hline & External Rating & & Self-Report & \multicolumn{1}{c}{$t$ value } \\
\cline { 2 - 2 } & Mean $(S D)$ & & Mean $(S D)$ & $28 d f$ \\
\hline Health and Safety & $2.79(1.32)$ & & $1.76(1.60)$ & $2.62^{* *}$ \\
Outdoor Environment & $2.38(1.72)$ & & $1.07(1.25)$ & $3.01^{\text {** }}$ \\
Indoor Environment & $8.59(3.04)$ & & $2.10(2.37)$ & $10.68^{* * *}$ \\
Family Involvement & $2.86(1.81)$ & & $1.00(1.20)$ & $5.17^{* * *}$ \\
Program & $4.90(1.86)$ & & $1.52(1.79)$ & $7.69^{* * *}$ \\
Administration & $2.83(1.44)$ & & $.76(1.15)$ & $7.16^{* * *}$ \\
\hline
\end{tabular}

Note. External Rating was an ECERS-R to CAC Comparison; External rating and self-report are dummy coded to indicate if the indicator were present either by director report or by rater report. ${ }^{* *} p \leq .01 ;{ }^{* * *} p \leq .001$ 
Table 6

The Number of CAC Quality Indicators Verified through External Rating that were Claimed or Unclaimed through Self-Report

\begin{tabular}{lccrr}
\hline CAC Quality Indicators & $\begin{array}{c}\text { Unclaimed but } \\
\text { verified (\%) }\end{array}$ & $\begin{array}{c}\text { Self-reported and } \\
\text { verified (\%) }\end{array}$ & Total \\
\hline Health and Safety & $54(64.3)$ & & $30(35.7)$ & 84 \\
Outdoor Environment & $53(76.8)$ & & $16(23.2)$ & 69 \\
Indoor Environment & $205(82.3)$ & & $44(17.7)$ & 249 \\
Family Involvement & $64(77.1)$ & & $19(22.9)$ & 83 \\
Program & $116(81.7)$ & & $26(18.3)$ & 142 \\
Administration & $68(82.9)$ & & $14(17.1)$ & 82 \\
\cline { 2 - 3 } Overall Total & $560(79.0)$ & & $149(21.0)$ & 709 \\
\hline
\end{tabular}

Note: For more information on CAC indicators, see Appendix A. 
Table 7

The Number of CAC Quality Indicators Not Externally Verified that were Claimed and Not Claimed through Self-Report

\begin{tabular}{lcccc}
\hline CAC Quality Indicators & $\begin{array}{c}\text { Self-reported but } \\
\text { not verified (\%) }\end{array}$ & $\begin{array}{c}\text { Not reported and } \\
\text { not verified (\%) }\end{array}$ & Total \\
\hline Health and Safety & $28(31.5)$ & & $61(68.5)$ & 89 \\
Outdoor Environment & $15(20.3)$ & & $59(79.7)$ & 74 \\
Indoor Environment & $17(9.2)$ & & $167(90.8)$ & 184 \\
Family Involvement & $10(11.0)$ & & $81(89.0)$ & 91 \\
Program & $18(12.2)$ & & $129(87.8)$ & 147 \\
Administration & $8(13.1)$ & & $53(86.9)$ & \\
\cline { 2 - 2 } \cline { 5 - 6 } Overall Total & $96(14.9)$ & & $550(85.1)$ & 646 \\
\hline
\end{tabular}

Note: For more information on CAC indicators, see Appendix A. 
Table 8

Counts Showing the Self-reported Quality Indicators (CAC) Validated by an External Rating of Quality (ECERS-R to CAC Comparison)

\begin{tabular}{|c|c|c|c|}
\hline CAC Quality Indicators & $\begin{array}{c}\text { Self-Reported and } \\
\text { Verified (\%) }\end{array}$ & $\begin{array}{l}\text { Self-Reported and } \\
\text { Unverified }(\%)\end{array}$ & Total \\
\hline Health and Safety & $30(51.7)$ & $28(48.3)$ & 58 \\
\hline Outdoor Environment & $16(51.6)$ & $15(48.4)$ & 31 \\
\hline Indoor Environment & $44(72.1)$ & $17(27.9)$ & 61 \\
\hline Family Involvement & $19(65.5)$ & $10(34.5)$ & 29 \\
\hline Program & $26(61.9)$ & $16(38.1)$ & 42 \\
\hline Administration & $14(63.6)$ & $8(36.4)$ & 22 \\
\hline Overall Total & $149(61.3)$ & $94(38.7)$ & 243 \\
\hline
\end{tabular}

Note: For more information on CAC indicators, see Appendix A. 
Figures

April 2014

\begin{tabular}{|l|}
\hline \multicolumn{1}{|c|}{ Environment and } \\
Goal Statement \\
What QRIS/CAC is \\
and does: \\
Recognizes quality \\
care, provides \\
standards that define \\
quality, quality \\
improvement \\
supports, financial \\
incentives, provides \\
parents with a list of \\
self-reported quality \\
indicators \\
Characteristics of \\
Families: \\
QRIS/CAC is \\
concerned about \\
raising quality of \\
care for all children, \\
especially children \\
with subsidies \\
Stakeholders: \\
Representatives \\
from the OCC, \\
Department of \\
Health, Nonprofits, \\
and Family and \\
Center \\
Administrators \\
\cline { 2 - 2 }
\end{tabular}

\begin{tabular}{|l|}
\multicolumn{1}{|c|}{ Inputs } \\
Administrative \\
Structure: Folded \\
within Office of \\
Child Care and the \\
regional CCRRs; no \\
additional resources \\
allocated \\
Standards or \\
Quality Indicators: \\
120 quality \\
indicators across 6 \\
subscales: Health \\
and Safety, Outdoor \\
Environment, \\
Indoor \\
Environment, \\
Family \\
Involvement, \\
Program, \\
Administration \\
Self-report Quality \\
Indicators: \\
Qualifying \\
documentation, \\
unique to each item, \\
is submitted for \\
every claimed \\
quality indicator \\
\hline
\end{tabular}

\begin{tabular}{|c|c|}
\hline $\begin{array}{l}\quad \text { Activities } \\
\text { 1. Self-reported } \\
\text { documentation is } \\
\text { reviewed by } \\
\text { external validators } \\
\text { from regional } \\
\text { CCRRs } \\
\text { 2. In-service support } \\
\text { is developed and } \\
\text { provided by regional } \\
\text { CCRRs } \\
\text { 3. Grants for toys } \\
\text { and materials } \\
\text { awarded depending } \\
\text { on \# of criteria } \\
\text { validated } \\
\text { Welcome grant: } \\
10 \text { quality criteria } \\
\text { achieved; grant } \\
\text { amounts range from } \\
\$ 350-\$ 1250 \\
\text { depending on center } \\
\text { capacity } \\
\text { Renewal grant: } \\
5-10 \text { criteria: } \$ 400 \\
11-20 \text { criteria: } \$ 800 \\
21-30 \text { criteria: } \\
\$ 120031-40 \\
\text { criteria: } \$ 160041+ \\
\text { criteria: } \$ 2000\end{array}$ & $\begin{array}{l}\quad \text { Outputs } \\
\text { At the time of this } \\
\text { study: } \\
\text { 1. 30\% of directors } \\
\text { participating } \\
\text { 2. Over } 6,744 \\
\text { criteria approved by } \\
\text { regional CCRRs } \\
\text { 3. 135 CAC grants } \\
\text { awarded between } \\
\text { April } 1,2013 \text { and } \\
\text { March } 31,2014 \\
\text { 4. 200,864 hits to } \\
\text { the CAC website } \\
\text { (since it was } \\
\text { developed in } \\
\text { 4/20/12) } \\
\text { 5. 10,000-12,000 } \\
\text { website hits per } \\
\text { month } \\
\text { 6. 3,000 referrals per } \\
\text { month }\end{array}$ \\
\hline
\end{tabular}

\section{Outcomes}

1. Directors' selfreports validated through outside study

2. Parents use website to compare child care quality 3. Child care programs in QRIS improve quality 4. Ongoing evolution of the QRIS program 
Figure captions:

Figure 1

Logic Model 